\title{
Epigenética del cáncer de mama
}

\author{
Epigenetics of breast cancer
}

Ismael Vásquez-Moctezuma, ${ }^{*}$ Estefanía Fernández-Navarrete, ${ }^{*}$

Juan Manuel Márquez-Mendoza, ${ }^{*}$ Gabriela Rebeca Luna-Palencia ${ }^{\ddagger}$

* Área de Morfología de la Maestría en Ciencias de la Salud de la Escuela Superior de Medicina del Instituto Politécnico Nacional, CDMX.

₹ Departamento de Biotecnología del CINVESTAV-IPN, CDMX

\section{Correspondencia:} Dr. Ismael VásquezMoctezuma

Salvador Díaz Mirón esq. Plan de San Luis S/N, Miguel Hidalgo, Casco de Santo Tomas, 11340 Ciudad de México, CDMX.

\section{RESUMEN}

Existen alteraciones genéticas bien caracterizadas que se relacionan de manera directa con la carcinogénesis, que incluyen amplificaciones, deleciones, mutaciones puntuales, reordenamientos cromosómicos y aneuploidía. Aparte de estas alteraciones se suman al origen del cáncer las alteraciones epigenéticas que generan una expresión de genes aberrantes y que contribuyen a la tumorigénesis. Se destaca que las modificaciones son de interés como blancos terapéuticos o en la prevención debido a que son reversibles. Las modificaciones epigenéticas son cambios moleculares que pueden modificar el fenotipo celular y el perfil de expresión génica de una célula, que son heredables durante la mitosis de las células somáticas (y algunas veces operan en la línea germinal), pero no incluyen cambios en la secuencia del ADN. Los mecanismos moleculares epigenéticos son la metilación del ADN, las modificaciones de histonas, los ARNs pequeños no codificantes o los ARN antisentido. Estas alteraciones están interconectadas y son importantes en el crecimiento y desarrollo normales de la glándula mamaria.

Palabras clave: Epigenética, cáncer de mama, HDACs, HATs, miARNs.

\section{ABSTRACT}

There are well-characterized genetic alterations directly related to carcinogenesis, including amplifications, deletions, point mutations, chromosomal rearrangements and aneuploidy. Apart from these alterations, epigenetic alterations that generate aberrant gene expression and contribute to tumorigenesis are added to the origin of cancer. It is emphasized that the modifications are of interest as therapeutic targets or in prevention because they are reversible. Epigenetic modifications are molecular changes that can modify the cellular phenotype and gene expression profile of a cell, which are heritable during somatic cell mitosis (and sometimes operate in the germline), but do not include changes in the sequence of the DNA. Epigenetic molecular mechanisms are DNA methylation, histone modifications, small non-coding RNAs, or antisense RNAs. These alterations are interconnected and are important in normal growth and development of the mammary gland.

Keywords: Epigenetics, breast cancer, HDACs, HATs, miRNAs.

Citar como: Vásquez-Moctezuma I, Fernández-Navarrete E, Márquez-Mendoza JM, Luna-Palencia GR. Epigenética del cáncer de mama. Rev Mex Mastol. 2020; 10 (2): 39-47. https://dx.doi.org/10.35366/97713 


\section{LA METILACIÓN DEL ADN Y SU PARTICIPACIÓN EN EL CÁNCER DE MAMA}

La metilación del ADN es la adición de un grupo metilo en el carbono cinco del anillo de la citocina. La metilación se realiza en las secuencias o «islas» 5'-CpG-3'. Estas islas tienen una longitud de entre 500 a 5,000 pb y se reparten aproximadamente cada 100 mil pares de bases. Aproximadamente, la mitad de los genes contiene este tipo de secuencias, y están presentes tanto en genes house keeping como en aquellos con patrones de expresión específicos de tejido. La metilación del ADN la realizan las enzimas ADN metiltransferasas (DNMT). Las DNMT transfieren grupos metilo, donados por la S-adenosil metionina, a las islas $\mathrm{CpG}^{1-3} \mathrm{En}$ el humano se sabe que las DNMT1, DNMT3a y DNMT3b tienen actividad catalítica de metiltransferasa. La enzima DNMT1 se dedica a hemimetilar sobre el ADN no metilado y tiene su actividad en los sitios de replicación. Por tanto, DNMT1 copia el patrón de metilación del ADN molde en la hebra hija recién sintetizada, por esta acción se le considera una metiltransferasa de mantenimiento de las metilaciones. La DNMT3a y DNMT3b son metiltransferasas de novo, tienen actividad de la metiltransferasa hacia el ADN no metilado. Normalmente estas enzimas DNMT se expresan de forma ubicua, en bajos niveles en tejidos. ${ }^{3}$ Sin embargo, se ha visto que se sobreexpresan en diferentes tipos de cáncer como: colorrectal, próstata, ovario, endometrio y mama. ${ }^{4-9}$

Con respecto al cáncer de seno, en un trabajo en el cual se evaluaron 130 carcinomas de mama no metastásicos unilaterales primarios, la cantidad de mRNA de las enzimas DNMT1, DNMT3a y DNMT3b se correlacionaron positivamente entre sí, esto sugiere una regulación coordinada. En 30\% de estas pacientes se detectó sobreexpresión de DNMT3b y sólo se identificó sobreexpresión de 5.4\% para DNMT1 y de $3.1 \%$ para DNMT3a. Se concluyó que una alta expresión de DNMT3b se correlaciona con mayor grado histológico, falta de receptor de estrogénico $\alpha$ y presencia del marcador de Ki67, lo que pudiera indicar la participación de DNMT3b en la progresión y agresividad del cáncer de mama. 4,5 También se asoció la alta expresión de DNMT3b con reducción del tiempo de supervivencia libre de enfermedad en el grupo de pacientes que recibieron terapia hormonal. ${ }^{4,5}$

La metilación de la isla $\mathrm{CpG}$ de las regiones promotoras puede afectar la expresión transcripcional de genes y estimular la carcinogénesis en dos situaciones: (I) las islas CpG normalmente no metiladas pueden metilarse de manera anormal generando el silenciamiento de genes supresores de tumores, y (II) las islas CpG que normalmente están metiladas pueden desmetilarse, esto lleva a la activación de oncogenes y retrotransposones. ${ }^{10}$ Otros genes silenciados por la hipermetilación son los que inhiben la invasión, la metástasis, la reparación del ADN, el receptor hormonal, la homeostasis celular, los de adhesión intercelular, así como los que inhiben la progresión del ciclo celular, la angiogénesis y la supervivencia celular. Hasta el momento, se han descrito más de 100 genes que están hipermetilados en líneas celulares y tumores de cáncer de mama. ${ }^{11,12}$ Existen ejemplos de genes cuyos promotores se metilan en el cáncer de mama: ciclina D2 (CCND2) que regula el ciclo celular, ${ }^{13}$ el gen p16ink4A/ CDKN2A que expresa un regulador del ciclo celular, el gen de la cadherina-3 $(\mathrm{CDH} 3)$ que codifica para una molécula de adhesión celular significativo para la invasión y metástasis, el factor High in normal-1 (HIN1) que es inhibidor del crecimiento celular, la migración y la invasión, los genes típicos del cáncer de mama como son ER- $\alpha$, ER- $\beta$ y BRCA1. ${ }^{13-19}$ La pérdida de expresión de ER- $\beta$ se asocia con la transición de carcinomas ductales in situ a invasivos, y este silenciamiento se relaciona con la hipermetilación. ${ }^{20}$ También existe metilación del promotor de BRCA1 en cánceres de mama esporádicos. ${ }^{21}$ Como se ve, el silenciamiento génico por hipermetilación de los promotores de los genes es un mecanismo común de carcinogénesis de mama, por lo que tiene un gran potencial para la prevención y el tratamiento del cáncer.

El análisis de alta resolución de la hipometilación de secuencias de ADN en el cáncer de mama demostró alrededor de 1,500 regiones hipometiladas de una manera específica. ${ }^{22,23}$

Aunque el cáncer de mama puede clasificarse en distintas subclases histológicas, no existen diferencias importantes en los patro- 
nes de metilación del ADN entre los cánceres de mama ductal y lobulillar. ${ }^{24,25}$ De manera independiente, se observaron diferentes perfiles epigenéticos en los tumores de mama clasificados según su estado del receptor hormonal. ${ }^{26}$ Los genes examinados estaban en menor medida metilados en tumores ER negativos en comparación con los positivos. Las mutaciones en el gen p53 también se han asociado con patrones de metilación diferencial en el cáncer de mama, donde los tumores con mutaciones de p53 suelen estar hipometilados en comparación con los tumores con p53 de tipo silvestre. ${ }^{26}$

\section{CAMBIOS DE ACETILACIÓN Y DESACETILACIÓN DE HISTONAS}

La regulación epigenética de los genes es un mecanismo en el que las enzimas acetiltransferasas de histonas (HAT) pegan acetilo en los aminoácidos lisina (grupo épsilon amino) de las colas de histona, lo que neutraliza la carga positiva es este aminoácido, relajando el ADN y permitiendo que las proteínas de la transcripción puedan acceder al gen, proceso asociado al encendido de genes. La eliminación de los grupos acetilo, por medio de las enzimas desacetilasas de histonas (HDACs), compacta el ADN sobre el octámero de histonas, de tal forma que el gen se apaga. ${ }^{27-29}$ Se conocen 18 HDAC humanas que se agrupan en cuatro clases de acuerdo con su homología con proteínas de levadura. Éstos son: clase I (HDAC1, 2, 3 y 8), clase II (HDAC4, 5, 6, 7, 9, 10), clase III o sirtuinas y son homólogas con Sir2 (SIRT1, $2,3,4,5,6$ y 7 ) y la clase IV (HDAC11) que tienen homología con las enzimas de clase I y II. El grupo de clase III es una categoría especial dado que depende de $\mathrm{NAD}^{+}$, mientras que los otros grupos requieren $\mathrm{Zn}^{2+}$ como cofactor. Debido a su importancia en la regulación de genes y su expresión diferente tanto en el mRNA como en la cantidad de proteínas, las HDAC son de gran interés en el cáncer, incluido el cáncer de mama. ${ }^{27}$ La expresión de HDAC1 se observó en $40 \%$ y HDAC3 en $44 \%$ de los casos de cáncer de mama, los niveles de proteína y de mRNA de HDAC1 y los niveles de proteína HDAC3 estaban elevados en tumores positivos para el ER y para el receptor de pro- gesterona (PR). ${ }^{30,31}$ La expresión de HDAC1 y HDAC3 se correlacionó con el receptor de hormonas esteroides, HER2/neu y el estado de proliferación del cáncer de mama. ${ }^{32,33}$ Esto se confirmó en pacientes con tumores de mama invasivos, ya que los niveles de expresión de la proteína HDAC1 predicen la supervivencia libre de enfermedad, pero no la supervivencia general. Se ha informado que la expresión de mRNA de HDAC6 es importante en tumores pequeños, de bajo grado, ER y PR positivos en comparación con cánceres con receptores de hormonas negativos de alto grado. ${ }^{34}$ Estos datos señalan que la investigación de HDAC puede aplicarse en el pronóstico del cáncer de mama y tratamientos específicos.

El cáncer de mama es heterogéneo, va desde hiperplasia premaligna hasta carcinomas invasivos y metastásicos. El análisis de un grupo bien caracterizado de carcinomas de mama mostró que existe correlación entre el estado global de las modificaciones de las histonas, el fenotipo del biomarcador tumoral y el resultado clínico. Se detectaron niveles altos de acetilación y metilación de histonas casi de manera exclusiva en tumores de mama de tipo luminal y esto se correlacionó con un buen pronóstico. ${ }^{35}$ Por el contrario, se detectó menor acetilación y metilación de histonas (como H3K18ac, H4K12ac, H3K4me2, H4K20me3 y H4R3me2) en los carcinomas basales y esto se asoció con una mala respuesta a los tratamientos. Este análisis también mostró que la mayoría de los casos de cáncer de seno tienen una acetilación del tipo H4K16ac en baja cantidad o ausente, lo que sugiere que esta modificación puede ser un marcador temprano de cáncer de mama. ${ }^{35,36}$ El cáncer de mama parece presentar cambios de histonas que controlan genes específicos. Se demostró que en la línea celular MCF-7/TAMR resistente al tamoxifeno de cáncer de mama, el ER- $\beta$ se silencia debido al reclutamiento de enzimas que producen modificaciones de histonas, y que crean un ambiente de heterocromatina en la vecindad del promotor, dificultando la transcripción del gen. ${ }^{3}$ En la región del promotor se observaron marcas de cromatina con cambios que indican represión como 2 meK9H3, 3meK9H3, 2me$\mathrm{K} 27 \mathrm{H} 3$ y 3 meK27H3. ${ }^{1-3}$ Esto es consistente con hallazgos previos con otros genes asociados con 
el control del crecimiento que muestran que 3 meK $27 \mathrm{H} 3$ está asociado con el silenciamiento de genes. ${ }^{37-39}$ Los patrones de expresión de enzimas que modifican histonas se asocian con el pronóstico del cáncer de mama. Se demostró que la sobreexpresión de enhancer of zeste homolog 2 (EZH2), que forma parte del complejo represivo polycomb 2 (PRC2) y su función es la metilación de la histona 3 lisina 27 (H3K27), se correlaciona con cáncer de mama agresivo y de mal pronóstico. ${ }^{40,41}$

\section{LOS MICRORNA EN EL CÁNCER DE MAMA}

Estos pequeños ARNs llamados microRNAs, de 17 a 22 bases de longitud, han inundado la literatura científica desde hace décadas. Para algunas de estas moléculas se conoce un poco de su función, de otras no tanto, pero lo que ha ayudado mucho son los estudios que correlacionan la abundancia de éstos con algún tipo de tumor, con la evolución y el pronóstico. Estos ARNs tienen una función importante en la regulación de procesos biológicos y patológicos. Su función se relaciona con el desarrollo de la glándula mamaria normal. Sin embargo, en un estudio comparativo que examinó la expresión de miRNA en mujeres jóvenes y adultas, durante el embarazo, la lactancia y la involución mamaria, se detectaron siete grupos de miRNAs, esto basado en su expresión temporal, asociando varias familias de miRNA con diferentes fases del ciclo mamario. ${ }^{42}$ Algunos miRNAs (el miR-25 y miR-17e92) se relacionan con el cáncer de mama basal agresivo y se expresan de manera primordial durante la pubertad y la gestación, lo que demuestra su participación en la fisiología mamaria. ${ }^{42}$ De manera adicional, los miRNA (como let-7), que están involucrados con el fenotipo diferenciado, aumentan durante la pubertad y el embarazo. Se observó mayor expresión de miR-29 durante la involución posterior a la lactación, esta evidencia indica que la expresión del miR-29 se involucra con la remodelación de la mama. Los perfiles de análisis de los miRNAs demuestran que se regulan con baja expresión en diferentes tipos de cáncer de seno.

Asimismo, se asoció la regulación a la baja de algunos miRNAs con características clínico-patológicas, como es el caso de ER/PgR positivos, tamaño del tumor, ganglios linfáticos y expresión de p53. En etapas tempranas de la progresión del cáncer de mama, la expresión de otro microARN Ilamado let-7 se elimina, mientras que su expresión se asocia con tumores luminales del tipo A de bajo grado y ER positivo. ${ }^{43,44}$ En modelos de ratón se observa que la expresión de let-7 está regulada a la baja en subpoblaciones de células mamarias con propiedades de tipo célula madre y durante la transición epitelio-mesénquima (EMT). ${ }^{45,46}$ Además, la falta de expresión de los miembros de la familia let-7 se correlaciona con características clínicas, como el estado de PR, ganglios linfáticos positivos (let-7f-1, let-7a-3 y let-7a-2) o un índice de proliferación elevado (let-7c y let-7d). ${ }^{47}$

\section{MIRNAS IMPORTANTES EN EL CÁNCER DE MAMA}

Los miR-34 (tres miRNAs) están regulados de manera positiva por la transcripción de p53 e influye en una serie de genes implicados en la proliferación celular y la apoptosis, incluido $\mathrm{BCl}-2 \cdot{ }^{48,49}$ En líneas celulares obtenidas a partir de tumores ER-/PR-/HER2-neu, los niveles de miR-34 son bajos, lo que demuestra la mayor incidencia de mutaciones en el gen p53 y la falta de función de la proteína en este subtipo tumoral..$^{50}$ En el desarrollo temprano del cáncer de mama se identificó la disminución de los miRNAs llamados miR-125a y miR-125b. La expresión del microRNA miR-205 se pierde al inicio del cáncer de mama, pero si su expresión persiste, entonces se relaciona con la presencia de marcadores inmunohistoquímicos basales, en los tumores ER/PR/HER2 negativos. ${ }^{43}$ El miR205 se correlaciona con el comportamiento de las células madre en una línea celular de la glándula mamaria murina, aunque en la mama madura se expresa principalmente en células mioepiteliales basales diferenciadas. ${ }^{45}$ Para el caso de la familia miR-10, que está formada por miR-10a y miR-10b, el miR-10a se encuentra sobreexpresado en el cáncer de mama y se correlaciona con el pronóstico en los tumores de mama ER positivos. ${ }^{51,52}$ También se ha demostrado que la sobreexpresión de miR-10b inicia la invasión y la metástasis en un 
modelo de xenoinjerto murino de cáncer de mama a través de su orientación a HOXD10. ${ }^{53}$ Uno de los primeros miRNAs oncogénicos caracterizados fue el miR-21, que se regula al alza en numerosos tumores, un hallazgo realizado en el glioblastoma y en el cáncer de mama. ${ }^{30,53}$ La expresión de este microRNA en los tumores de mama se correlacionó con la metástasis en estadio avanzado y se caracteriza por una supervivencia deficiente de manera independiente del grado y el estadio. ${ }^{31,55} \mathrm{La}$ eliminación de miR-21, por medio de ARN antisentido, reduce el crecimiento tumoral derivado de la línea de cáncer de mama triple negativa MCF-7 en modelos de xenoinjerto mediante la disminución de la proliferación y el aumento de la apoptosis, posiblemente debido a que el mRNA de Bcl-2 es objetivo de estos microRNAs. ${ }^{56}$ Se han detectado más blancos de miR-21 que incluyen la fosfatasa supresora de tumores PTEN en el carcinoma hepatocelular y mamario. ${ }^{31}$ El grupo miR-17e92 inhibe la proliferación de células de cáncer de seno en cultivo celular, dirigiéndose directamente a la ciclina D1. ${ }^{31}$ Se informó que otros miembros del grupo estaban sobreexpresados en tumores sólidos, incluidos los de pulmón y mama. ${ }^{47}$ Existe evidencia de que las firmas de expresión de miRNA pueden utilizarse en el futuro como biomarcadores tumorales para el diagnóstico y la estratificación del riesgo de los pacientes.

\section{ESTRATEGIAS EPIGENÉTICAS COMO TRATAMIENTO DEL CÁNCER DE MAMA}

En la actualidad, las nuevas estrategias de tratamiento que se centran en las alteraciones epigenéticas ofrecen más esperanza que las terapias existentes debido a la reversibilidad de las modificaciones epigenéticas. El establecimiento y mantenimiento de alteraciones epigenéticas se basan en las funciones de las enzimas DNMT y HDAC, que son los principales objetivos de la terapia epigenética. Los tratamientos epigenéticos actuales del cáncer de mama se enfocan en revertir la metilación alterada del ADN y la acetilación de histonas que controlan los genes supresores de tumores. Las combinaciones de terapias dirigidas que utilizan agentes epigenéticos con fármacos quimioterapéuticos conven- cionales son prometedoras para resensibilizar tumores quimiorresistentes. ${ }^{57}$

\section{INHIBIDORES DE LAS ENZIMAS DNMTS Y HDACS COMO TRATAMIENTO EPIGENÉTICO}

Los fármacos que se utilizan para eliminar la metilación son azacitidina (5-azacitidina), decitabina (5-aza-2'-desoxicitidina, 5-aza-dc), fazarabina (1- $\beta$-d-arabinofurasonil-5-azacitosina) y dihidro-5-azacitidina. ${ }^{58}$ Estos son derivados de la desoxicitidina con algunas modificaciones en la quinta posición del anillo de pirimidina. La zebularina y los oligodesoxinucleótidos antisentido también se utilizan para modificar la metilación del ADN. ${ }^{59}$ La 5-azacitidina se usó originalmente como antimetabolito nucleósido con especificidad clínica para tratar la leucemia mieloide aguda. ${ }^{60}$ Debido a que es capaz de activarse al nucleósido trifosfato e incorporarse tanto en el ADN como en el ARN, el tratamiento de las células con 5 -azacitidina condujo a la inhibición de la síntesis de ADN, ARN y proteínas. ${ }^{61}$ Otro fármaco la 5 -aza-dc sólo se incorpora al ADN y es 10 veces más citotóxico que la 5-azacitidina para células y animales en cultivo. ${ }^{62}$ La incorporación de 5-aza o 5-aza2 '-dc en el ADN de las células cultivadas lleva a una pérdida de la enzima DNMT porque se une de manera irreversible al ADN. ${ }^{63}$ Estudios preclínicos con 5-aza-2'-dc han demostrado que disminuye la metilación en varias líneas celulares y en células de pacientes con leucemia humana. ${ }^{64,65}$ Los ensayos clínicos en tumores mostraron tasas de respuesta inferiores a $10 \%{ }^{58}$ Sin embargo, los ensayos sobre neoplasias hematológicas han tenido más éxito. Un estudio aleatorizado evaluó la combinación de amsacrina y etopósido con los mismos dos agentes más 5-aza-dc para el tratamiento de la leucemia mieloide aguda infantil resistente a la inducción. La tasa de respuesta fue mayor con la combinación de tres fármacos. ${ }^{66}$

Con respecto a los inhibidores de HDACs se agrupan en varias clases estructurales, incluidos hidroxamatos, péptidos cíclicos, ácidos alifáticos y benzamidas. ${ }^{67}$ Entre estos fármacos tenemos a la tricostatina A (TSA) [7- [4- (dimetilamino) fenil] -N-hidroxi-4,6-dimetil-7-oxo(2E, 4E, 6R) -2,4 heptadienamida], un inhibidor 
de HDAC, se aisló inicialmente como un agente antimicótico. Sin embargo, se ha demostrado que es un agente anticanceroso que estimula la diferenciación de las células de eritroleucemia murina (MEL) y se identifica como un agente que actúa sobre las enzimas HDACs. También se ha demostrado que la TSA tiene la capacidad de detener células en las fases G1 y G2 del ciclo celular, provocar diferenciación y revertir la morfología maligna de las células en cultivo. ${ }^{68}$ El ácido hidroxámico suberoilanilida (SAHA) [N-hidroxi-N-feniloctanodiamida, vorinostat, Zolinza ${ }^{\circledR}$ ] es un ácido hidroxámico, se correlaciona estructuralmente con el producto natural TSA. Los ácidos hidroxámicos tienen una alta afinidad por el Fe (III), Ni (II) y Zn (II). ${ }^{69}$ El SAHA genera una fuerte inhibición a concentraciones nanomolares para HDAC de clase I y clase II a través de la coordinación con el cofactor catalítico de Zn (II). ${ }^{70}$ Los inhibidores de HDAC estimulan el aumento en el estado de acetilación de histonas y factores de transcripción que resulta tanto al aumento como al descenso de la expresión de un número limitado de genes. ${ }^{71,72}$ Los inhibidores de HDAC estimulan la expresión del gen p21WAF1, lo que se asocia con un aumento en la acetilación de histonas dentro de la región promotora de p21WAF1. ${ }^{73,74}$ Estos datos indican que p21WAF1 es un gen blanco de los inhibidores de HDAC. También se ha demostrado que SAHA provoca modificaciones específicas en la acetilación y metilación de lisinas en las histonas $\mathrm{H} 3$ y $\mathrm{H} 4$ dentro del promotor del gen p21WAF1. ${ }^{73}$

Se sabe que la hipermetilación del gen ER- $\beta$ está implicada en el desarrollo de resistencia al tamoxifeno. ${ }^{75}$ Existen enfoques para superar la resistencia al tamoxifeno por medio del uso de inhibidores de HDAC y DNMT combinados con el tamoxifeno. En la línea celular derivada de melanoma MDA-MB-435, con fenotipo de receptores ER-negativo y PR-negativo, ER- $\alpha$ se reexpresó mediante tratamiento con 5 -aza-dc o TSA. ${ }^{76}$

\section{CONCLUSIONES}

El conocimiento acumulado sobre los procesos epigenéticos así como el mapeo de los genes regulados por estos mecanismos, como es el caso de las secuencias de ADN hipometiladas e hipermetiladas y cómo impacta la regulación de genes en los diferentes tipos de cáncer humano, la caracterización de las miríadas de genes que codifica para la familia de los miARNs y la regulación postraduccional de las colas de histonas por mecanismos de acetilación y desacetilación, nos llevará a diseñar tratamientos combinados entre las terapias clásicas contra el cáncer humano y las novedosas terapias epigenéticas.

Aparentemente, las células cancerosas adquieren un patrón complejo de lesiones genéticas y epigenéticas que pueden incluso llegar a interrelacionarse. Por el contrario, las aberraciones estructurales en el gen DNMT3b pueden ser en parte responsables del aumento de la expresión de DNMT3b y, en consecuencia, de la hipermetilación de genes críticos en tumores humanos. Agregando complejidad a esto, tales relaciones genéticas-epigenéticas específicas pueden no encontrarse necesariamente en todos los tipos de tumores; la metilación de BRCA1, por ejemplo, se observa únicamente en los cánceres de mama y ovario, pero está casi ausente en otros tipos de cáncer. Se requieren más investigaciones para desentrañar la pregunta de cómo se establece y mantiene el hipermetiloma en una célula cancerosa. El uso de alteraciones epigenéticas como medio de detección de tumores o tejidos adyacentes puede ayudar a los médicos a mejorar el pronóstico y brindar opciones de tratamiento más efectivas para pacientes con cáncer de mama.

\section{AGRADECIMIENTOS}

Agradecemos el apoyo del CONACYT a los becarios de maestría: Estefanía Fernández Navarrete (CVU 1019994), Juan Manuel Márquez Mendoza (CVU 956327). Este trabajo es parte del proyecto de investigación apoyado por la SIP (20200722).

\section{BIBLIOGRAFÍA}

1. Brait M, Sidransky D. Cancer epigenetics: above and beyond. Toxicol Mech Methods. 2011; 21 (4): 275278.

2. Bannister AJ, Kouzarides T. Regulation of chromatin by histone modifications. Cell Res. 2011; 21 (3): 381-395.

3. Bogdanović O, Lister R. DNA methylation and the preservation of cell identity. Curr Opin Genet Dev. 2017; 46: 9-14. 
4. Kanai Y, Hirohashi S. Alterations of DNA methylation associated with abnormalities of DNA methyltransferases in human cancers during transition from a precancerous to a malignant state. Carcinogenesis. 2007; 28 (12): 2434-2442.

5. Girault I, Tozlu S, Lidereau R, Bieche I. Expression analysis of DNA methyltransferases 1,3A, and 3B in sporadic breast carcinomas. Clin Cancer Res. 2003; 9 (12): 4415-4422.

6. Issa JP, Vertino PM, Wu J, Sazawal S, Celano P, Nelkin $\mathrm{BD}$ et al. Increased cytosine DNA-methyltransferase activity during colon cancer progression. J Natl Cancer Inst. 1993; 85 (15): 1235-1240.

7. Mizuno S, Chijiwa T, Okamura T, Akashi K, Fukumaki $\mathrm{Y}$, Niho $\mathrm{Y}$ et al. Expression of DNA methyltransferases DNMT1, 3A, and 3B in normal hematopoiesis and in acute and chronic myelogenous leukemia. Blood. 2001; 97 (5): 1172-1179.

8. Eads CA, Danenberg KD, Kawakami K, Saltz LB, Danenberg PV, Laird PW. CpG island hypermethylation in human colorectal tumors is not associated with DNA methyltransferase overexpression. Cancer Res. 1999; 59 (10): 2302-2306.

9. Patra SK, Patra A, Zhao H, Dahiya R. DNA methyltransferase and demethylase in human prostate cancer. Mol Carcinog. 2002; 33 (3): 163-171.

10. Jovanovic J, Ronneberg JA, Tost J, Kristensen V. The epigenetics of breast cancer. Mol Oncol. 2010; 4 (3): 242-254.

11. Hinshelwood RA, Clark SJ. Breast cancer epigenetics: normal human mammary epithelial cells as a model system. J Mol Med (Berl). 2008; 86 (12): 1315-1328.

12. Widschwendter $M$, Jones PA. DNA methylation and breast carcinogenesis. Oncogene. 2002; 21: 54625482.

13. Evron E, Dooley WC, Umbricht CB, Rosenthal D, Sacchi N, Gabrielson E et al. Detection of breast cancer cells in ductal lavage fluid by methylation-specific PCR. Lancet. 2001; 357 (9265): 1335-1336.

14. Herman JG, Merlo A, Mao L, Lapidus RG, Issa JP, Davidson NE et al. Inactivation of the CDKN2/p16/ MTS1 gene is frequently associated with aberrant DNA methylation in all common human cancers. Cancer Res. 1995; 55 (22): 4525-4530.

15. Graff JR, Herman JG, Lapidus RG, Chopra H, Xu R, Jarrard DF et al. E-cadherin expression is silenced by DNA hypermethylation in human breast and prostate carcinomas. Cancer Res. 1995; 55 (22): 5195-5199.

16. Romanov SR, Kozakiewicz BK, Holst CR, Stampfer MR, Haupt LM, Tlsty TD. Normal human mammary epithelial cells spontaneously escape senescence and acquire genomic changes. Nature. 2001; 409 (6820): 633-637.

17. Krop I, Parker MT, Bloushtain-Qimron N, Porter D, Gelman R, Sasaki H et al. HIN-1, an inhibitor of cell growth, invasion, and AKT activation. Cancer Res. 2005; 65 (21): 9659-9669.

18. Krop IE, Sgroi D, Porter DA, Lunetta KL, LeVangie $\mathrm{R}$, Seth $\mathrm{P}$ et al. HIN-1, a putative cytokine highly expressed in normal but not cancerous mammary epithelial cells. Proc Natl Acad Sci USA. 2001; 98 (17): 9796-9801.

19. Yang X, Yan L, Davidson NE. DNA methylation in breast cancer. Endocr Relat Cancer. 2001; 8 (2): 115-127.
20. Skliris GP, Munot K, Bell SM, Carder PJ, Lane S, Horgan $K$ et al. Reduced expression of oestrogen receptor beta in invasive breast cancer and its re-expression using DNA methyl transferase inhibitors in a cell line model. J Pathol. 2003; 201 (2): 213-220.

21. Dobrovic A, Simpfendorfer D. Methylation of the BRCA1 gene in sporadic breast cancer. Cancer Res. 1997; 57 (16): 3347-3350.

22. Novak P, Jensen T, Oshiro MM, Watts GS, Kim CJ, Futscher BW. Agglomerative epigenetic aberrations are a common event in human breast cancer. Cancer Res. 2008; 68 (20): 8616-8625.

23. Shann YJ, Cheng C, Chiao CH, Chen DT, Li PH, Hsu MT. Genome-wide mapping and characterization of hypomethylated sites in human tissues and breast cancer cell lines. Genome Res. 2008; 18 (5): 791801.

24. Bae YK, Brown A, Garrett E, Bornman D, Fackler MJ, Sukumar S et al. Hypermethylation in histologically distinct classes of breast cancer. Clin Cancer Res. 2004; 10 (18): 5998-6005.

25. Fackler MJ, McVeigh M, Evron E, Garrett E, Mehrotra J, Polyak $\mathrm{K}$ et al. DNA methylation of RASSF1A, HIN-1, RAR-beta, Cyclin D2 and twist in in situ and invasive lobular breast carcinoma. Int J Cancer. 2003; 107 (6): 970-975.

26. Feng $\mathrm{W}$, Shen L, Wen S, Rosen DG, Jelinek J, Hu X et al. Correlation between CpG methylation profiles and hormone receptor status in breast cancers. Breast Cancer Res. 2007; 9 (4): R57.

27. Haberland M, Montgomery RL, Olson EN. The many roles of histone deacetylases in development and physiology: implications for disease and therapy. Nat Rev Genet. 2009; 10 (1): 32-42.

28. Bosch-Presegue L, Vaquero A. The dual role of sirtuins in cancer. Genes Cancer. 2011; 2 (6): 648-662.

29. Peng L, Seto E. Deacetylation of nonhistone proteins by HDACs and the implications in cancer. Handb Exp Pharmacol. 2011; 206: 39-56.

30. Iorio MV, Ferracin M, Liu CG, Veronese A, Spizzo R, Sabbioni $\mathrm{S}$ et al. MicroRNA gene expression deregulation in human breast cancer. Cancer Res. 2005; 65 (16): 7065-7070.

31. Huang GL, Zhang $X \mathrm{H}$, Guo GL, Huang $K T$, Yang $K Y$, Shen $X$ et al. Clinical significance of miR-21 expression in breast cancer: SYBR-Green I-based real-time RT-PCR study of invasive ductal carcinoma. Oncol Rep. 2009; 21 (3): 673-679.

32. Zhang Z, Yamashita H, Toyama T, Sugiura H, Ando Y, Mita K et al. Quantitation of HDAC1 mRNA expression in invasive carcinoma of the breast. Breast Cancer Res Treat. 2005; 94 (1): 11-16.

33. Krusche CA, Wulfing P, Kersting C, Vloet A, Bocker W, Kiesel $L$ et al. Histone deacetylase- 1 and -3 protein expression in human breast cancer: a tissue microarray analysis. Breast Cancer Res Treat. 2005; 90 (1): 15-23.

34. Saji S, Kawakami M, Hayashi S, Yoshida N, Hirose M, Horiguchi S et al. Significance of HDAC6 regulation via estrogen signaling for cell motility and prognosis in estrogen receptor-positive breast cancer. Oncogene. 2005; 24 (28): 4531-4539.

35. Chervona Y, Costa M. Histone modifications and cancer: biomarkers of prognosis? Am J Cancer Res. 2012; 2 (5): 589-597. 
36. Elsheikh SE, Green AR, Rakha EA, Powe DG, Ahmed $\mathrm{RA}$, Collins $\mathrm{HM}$ et al. Global histone modifica tions in breast cancer correlate with tumor phenotypes, prognostic factors, and patient outcome. Cancer Res. 2009; 69 (9): 3802-3809.

37. Cao R, Wang L, Wang $\mathrm{H}$, Xia L, Erdjument-Bromage $\mathrm{H}$, Tempst $\mathrm{P}$ et al. Role of histone H3 lysine 27 methylation in Polycomb-group silencing. Science. 2002; 298 (5595): 1039-1043.

38. Kuzmichev A, Nishioka K, Erdjument-Bromage $\mathrm{H}$, Tempst P, Reinberg D. Histone methyltransferase activity associated with a human multiprotein complex containing the enhancer of Zeste protein. Genes Dev. 2002; 16 (22): 2893-2905.

39. Kirmizis A, Bartley SM, Kuzmichev A, Margueron R, Reinberg D, Green R et al. Silencing of human polycomb target genes is associated with methylation of histone H3 Lys 27. Genes Dev. 2004; 18 (13): 1592-1605.

40. Kleer CG, Cao Q, Varambally S, Shen R, Ota I, Tomlins $\mathrm{SA}$ et al. EZH2 is a marker of aggressive breast cancer and promotes neoplastic transformation of breast epithelial cells. Proc Natl Acad Sci USA. 2003; 100 (20): 11606-11611.

41. Pietersen AM, Horlings HM, Hauptmann M, Langerod A, Ajouaou A, Cornelissen-Steijger P et al. EZH2 and BMI1 inversely correlate with prognosis and TP53 mutation in breast cancer. Breast Cancer Res. 2008; 10 (6): R109.

42. Avril-Sassen S, Goldstein LD, Stingl J, Blenkiron C, Le Quesne J, Spiteri I et al. Characterization of microRNA expression in post-natal mouse mammary gland development. BMC Genomics. 2009; 10: 548.

43. Sempere LF, Christensen M, Silahtaroglu A, Bak M, Heath $\mathrm{CV}$, Schwartz G et al. Altered microRNA expression confined to specific epithelial cell subpopulations in breast cancer. Cancer Res. 2007; 67 (24): 11612-11620.

44. Blenkiron C, Goldstein LD, Thorne NP, Spiteri I, Chin SF, Dunning MJ et al. MicroRNA expression profiling of human breast cancer identifies new markers of tumor subtype. Genome Biol. 2007; 8 (10): R214.

45. Ibarra I, Erlich Y, Muthuswamy SK, Sachidanandam $R$, Hannon GJ. A role for microRNAs in maintenance of mouse mammary epithelial progenitor cells. Genes Dev. 2007; 21 (24): 3238-3243.

46. Dangi-Garimella S, Yun J, Eves EM, Newman M, Erkeland SJ, Hammond SM et al. Raf kinase inhibitory protein suppresses a metastasis signaling cascade involving LIN28 and let-7. EMBO J. 2009; 28 (4): 347-358.

47. Lu J, Getz G, Miska EA, Alvarez-Saavedra E, Lamb J, Peck D et al. MicroRNA expression profiles classify human cancers. Nature. 2005; 435 (7043): 834-838.

48. Bommer GT, Gerin I, Feng Y, Kaczorowski AJ, Kuick R, Love RE et al. p53-mediated activation of miRNA34 candidate tumor-suppressor genes. Curr Biol. 2007; 17 (15): 1298-1307.

49. Zhang L, Huang J, Yang N, Greshock J, Megraw MS, Giannakakis A et al. microRNAs exhibit high frequency genomic alterations in human cancer. Proc Natl Acad Sci USA. 2006; 103 (24): 9136-9141.

50. Kato M, Paranjape T, Muller RU, Nallur S, Gillespie E, Keane $\mathrm{K}$ et al. The mir-34 microRNA is required for the DNA damage response in vivo in C. elegans and in vitro in human breast cancer cells. Oncogene. 2009; 28 (25): 2419-2424.
51. Hoppe R, Achinger-Kawecka J, Winter S, Fritz P, Lo WY, Schroth W et al. Increased expression of miR-126 and miR-10a predict prolonged relapse-free time of primary oestrogen receptor-positive breast cancer following tamoxifen treatment. Eur J Cancer. 2013; 49 (17): 3598-3608.

52. Parrella P, Barbano R, Pasculli B, Fontana A, Copetti M, Valori VM et al. Evaluation of microRNA-10b prognostic significance in a prospective cohort of breast cancer patients. Mol Cancer. 2014; 13: 142.

53. Ma L, Teruya-Feldstein J, Weinberg RA. Tumour invasion and metastasis initiated by microRNA-10b in breast cancer. Nature. 2007; 449 (7163): 682-688.

54. Chan JA, Krichevsky AM, Kosik KS. MicroRNA-21 is an antiapoptotic factor in human glioblastoma cells. Cancer Res. 2005; 65 (14): 6029-6033.

55. Yan LX, Huang XF, Shao Q, Huang MY, Deng L, Wu $\mathrm{QL}$ et al. MicroRNA miR-21 overexpression in human breast cancer is associated with advanced clinical stage, lymph node metastasis and patient poor prognosis. RNA. 2008; 14 (11): 2348-2360.

56. Si ML, Zhu S, Wu H, Lu Z, Wu F, Mo YY. miR-21-mediated tumor growth. Oncogene. 2007; 26 (19): 2799-2803.

57. Luna-Palencia GR, Correa-Basurto J, Vásquez-Moctezuma I. El ácido valproico como agente sensibilizador al tratamiento anticáncer. Gac Med Mex. 2019; 155 (4): 417-422

58. Goffin J, Eisenhauer E. DNA methyltransferase inhibitors-state of the art. Ann Oncol. 2002; 13 (11): 1699-1716

59. Cheng JC, Matsen CB, Gonzales FA, Ye W, Greer S, Marquez VE et al. Inhibition of DNA methylation and reactivation of silenced genes by zebularine. J Natl Cancer Inst. 2003; 95 (5): 399-409.

60. Cihak A. Biological effects of 5-azacytidine in eukaryotes. Oncology. 1974; 30 (5): 405-422.

61. Cihak A, Vesely J. Effects of 5-aza-2'-deoxycytidine on DNA synthesis in mouse lymphatic tissues. Neoplasma. 1978; 25 (4): 385-393.

62. Flatau E, Gonzales FA, Michalowsky LA, Jones PA. DNA methylation in 5-aza-2'-deoxycytidine-resistant variants of C3H 10T1/2 C18 cells. Mol Cell Biol. 1984; 4 (10): 2098-2102.

63. Christman JK, Schneiderman N, Acs G. Interaction of DNA methyltransferase and other non-histone proteins isolated from friend erythroleukemia cell nuclei with 5-azacytosine residues in DNA. Prog Clin Biol Res. 1985; 198: 105-118.

64. Momparler RL, Bouchard J, Onetto N, Rivard GE. 5-aza-2'-deoxycytidine therapy in patients with acute leukemia inhibits DNA methylation. Leuk Res. 1984; 8 (2): 181-185.

65. Momparler RL, Momparler LF, Samson J. Comparison of the antileukemic activity of 5-AZA-2'-deoxycytidine, 1-beta-d arabinofuranosylcytosine and 5-azacytidine against L1210 leukemia. Leuk Res. 1984; 8 (6): 1043 1049.

66. Steuber CP, Krischer J, Holbrook T, Camitta B, Land $\mathrm{V}$, Sexauer $\mathrm{C}$ et al. Therapy of refractory or recurrent childhood acute myeloid leukemia using amsacrine and etoposide with or without azacitidine: a Pediatric Oncology Group randomized phase II study. J Clin Oncol. 1996; 14: 1521-1525. 
67. Miller TA, Witter DJ, Belvedere S. Histone deacetylase inhibitors. J Med Chem. 2003; 46 (5): 5097 5116.

68. Yoshida M, Horinouchi S, Beppu T. Trichostatin A and trapoxin: novel chemical probes for the role of histone acetylation in chromatin structure and function. Bioessays. 1995; 17 (5): 423-430.

69. Codd R, Braich N, Liu J, Soe CZ, Pakchung AA. Zn(II)dependent histone deacetylase inhibitors: suberoylanilide hydroxamic acid and trichostatin A. Int J Biochem Cell Biol. 2009; 41 (4): 736-739.

70. Richon VM, Emiliani S, Verdin E, Webb Y, Breslow $\mathrm{R}$, Rifkind RA et al. A class of hybrid polar inducers of transformed cell differentiation inhibits histone deacetylases. Proc Natl Acad Sci USA. 1998; 95 (6): 3003-3007.

71. Butler LM, Zhou X, Xu WS, Scher HI, Rifkind RA, Marks PA et al. The histone deacetylase inhibitor SAHA arrests cancer cell growth, up-regulates thioredoxin-binding protein-2, and down-regulates thioredoxin. Proc Natl Acad Sci USA. 2002; 99 (18): 11700-11705.
72. Glaser KB, Li J, Staver MJ, Wei RQ, Albert DH, Davidsen SK. Role of class I and class II histone deacetylases in carcinoma cells using siRNA. Biochem Biophys Res Commun. 2003; 310 (2): 529-536.

73. Gui CY, Ngo L, Xu WS, Richon VM, Marks PA. Histone deacetylase (HDAC) inhibitor activation of p21WAF1 involves changes in promoter-associated proteins, including HDAC1. Proc Natl Acad Sci USA. 2004; 101 (5): 1241-1246.

74. Richon VM, Zhou X, Secrist JP, Cordon-Cardo C, Kelly WK, Drobnjak M et al. Histone deacetylase inhibitors: assays to assess effectiveness in vitro and in vivo Methods Enzymol. 2004; 376: 199-205.

75. Chang HG, Kim SJ, Chung KW, Noh DY, Kwon Y, Lee ES et al. Tamoxifen-resistant breast cancers show less frequent methylation of the estrogen receptor beta but not the estrogen receptor alpha gene. J Mol Med (Berl). 2005; 83 (2): 132-139.

76. Yang X, Ferguson AT, Nass SJ, Phillips DL, Butash KA, Wang $\mathrm{SM}$ et al. Transcriptional activation of estrogen receptor alpha in human breast cancer cells by histone deacetylase inhibition. Cancer Res. 2000; 60 (24): 6890-6894. 